\title{
The breeding biology of Chinese Crested Terns in mixed species colonies in eastern China
}

\author{
S. H. CHEN, Z. Y. FAN, C. S. CHEN and Y. W. LU
}

\section{Summary}

The Chinese Crested Tern Thalasseus bernsteini is a Critically Endangered species and very little is known about its breeding biology and behaviour. Only two small breeding colonies have been recorded on the eastern coast of China. Between 2004 and 2009, their breeding biology was studied in two mixed species colonies on the Jiushan and Wuzhishan archipelagos in Zhejiang province. Chinese Crested Terns started breeding in late May and departed in late August, and nests were generally found within large colonies of Greater Crested Terns T. bergii. The nesting grounds of the mixed colony included grass, rock and interlaced zones on small, uninhabited islets. A total of six Chinese Crested Tern nests were identified, four of which were monitored. In these, the average clutch size was one, with an incubation period of 22-28 days and a fledging period of 31-35 days. The chicks subsequently joined chicks of the Greater Crested Tern, forming the same crèche. Adult Chinese Crested Terns foraged within approximately $5 \mathrm{~km}$ of the breeding islets and fed their chicks mainly with small and/or young shoaling fishes. The breeding success of Chinese Crested Tern was 100\% in both 2008 and 2009. In addition to mixed nesting, other traits of breeding biology, such as breeding site shifts and re-nesting, provide valuable information for surveying, monitoring and conservation of the Chinese Crested Tern.

\section{Introduction}

Despite being discovered, described and named in 1863, the Chinese Crested Tern Thalasseus bernsteini is still a poorly understood species. Prior to the 1930s, only a few specimens were collected from China, Thailand, the Philippines, Malaysia and Indonesia (Collar et al. 2001). Based on these specimens, the distribution of the species was generally described as either "unknown" or "breeding along the coastal areas of Eastern China and wintering in Indonesia and the Philippines" (Hsu and Melville 1994, del Hoyo et al. 1996, Zheng and Wang 1998, Collar et al. 2001). After a report of the collection of 21 birds from Muguan Dao and Tsangkow, a group of islands near Qingdao, Shandong Province of eastern China in June and July 1937 (Shaw 1938), the species disappeared for 63 years, apart from several unconfirmed sightings in the countries mentioned above, and in Cambodia and Singapore (Collar et al. 2001). In June 2000, four breeding pairs of the Chinese Crested Tern were observed within a large Greater Crested Tern T. bergii breeding colony on the Matzu archipelago, on the coast of Fujian Province, eastern China, which proved that the species was still extant (Liang et al. 200o). Subsequently another small breeding population was found on the Jiushan archipelago in coastal Zhejiang Province, eastern China in August 2004 (Chen et al. 2005). In 2008, the breeding population originally found on Jiushan had reportedly moved to the Wuzhishan archipelago, which belongs to the Zhoushan Group located in the northern coastal areas of Zhejiang. At this point, only the two aforementioned breeding populations of Chinese Crested Tern had been documented, and the global population of the species was estimated to be no more than 50 individuals (Chen et al. 
2009). The Chinese Crested Tern was listed as 'Critically Endangered' by IUCN and BirdLife International (BirdLife International 2009, IUCN 2009).

Currently, very little is known about the breeding biology and behaviour of the Chinese Crested Tern. Species such as terns and beach-nesting shorebirds and gulls are extremely vulnerable to disturbance, habitat loss, predation, fishing and hunting (e.g. Zavalaga et al. 2009, Jiang et al. 2010, Maguire et al. in press, Yorio et al. in press) and an understanding of the breeding biology of these species is essential to allow the formulation of effective conservation plans. We studied the breeding biology of Chinese Crested Terns on the Wuzhishan archipelago during the breeding seasons of 2008 and 2009. In addition, we made various opportunistic observations of the breeding population at the Jiushan archipelago in 2004 and 2007. This paper provides the first description of the breeding biology and life history traits of the Chinese Crested Tern.

\section{Methods}

Jiushan archipelago $\left(122^{\circ} 10^{\prime} \mathrm{E}, 29^{\circ} 26^{\prime} \mathrm{N}\right)$ is situated $19 \mathrm{~km}$ off the coast of Xiangshan county, eastern Zhejiang (Figure 1). Chinese Crested Terns were found breeding on islet A in 2004 (Chen et al. 2005) and on the same islet in 2007 (Chen et al. 2009). The Wuzhishan archipelago $\left(121^{\circ} 5 \mathrm{O}^{\prime} \mathrm{E}, 30^{\circ} 13^{\prime} \mathrm{N}\right)$ is located at the mouth of Hangzhou bay and to the north-west of the Zhoushan Group. This archipelago contains seven uninhabited islands ranging in size from 0.4 ha to 14.I ha. Four islands were used as nesting sites for several waterbird species, including Chinese Egret Egretta eulophotes, Little Egret E. garzetta, Black-tailed Gull Larus crassirostris, Greater Crested Tern, Black-naped Tern Sterna sumatrana, and Eurasian Oystercatcher Haematopus ostralegus (Wang et al. 2008). The Chinese Crested Tern was found to breed on

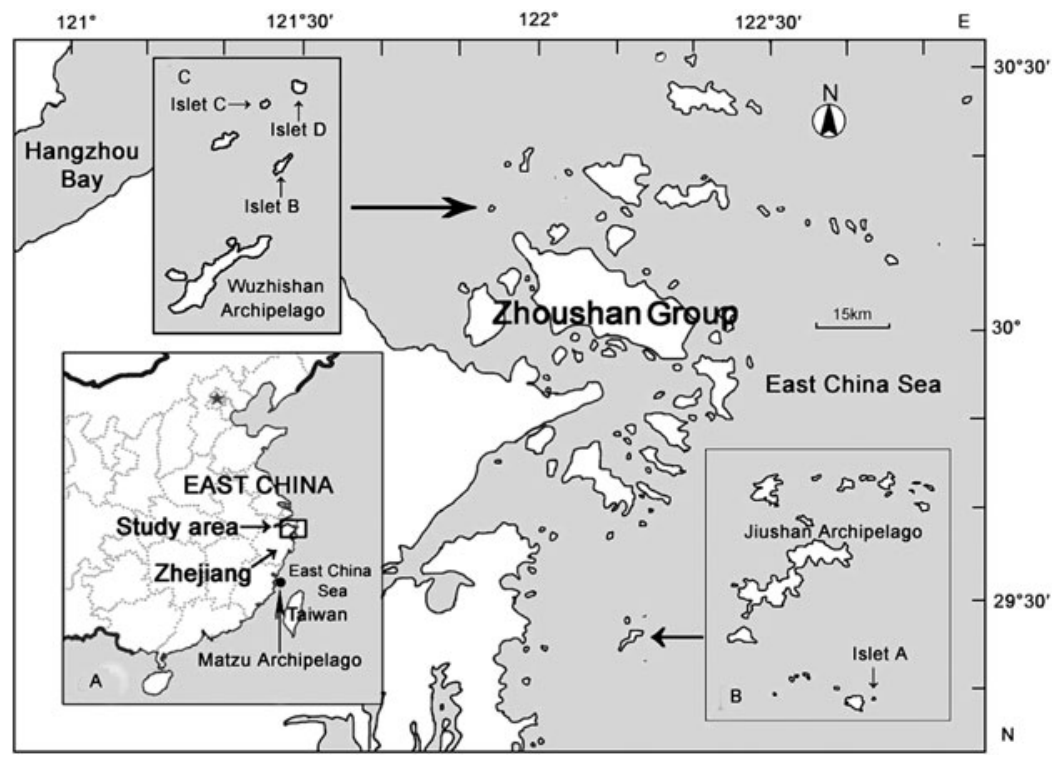

Figure 1. Breeding locations of the Chinese Crested Tern. Inset box A shows the study area and the Matzu archipelago where the first Chinese Crested Tern breeding colony was found; Box B shows the Jiushan archipelago and islet A where the Chinese Crested Tern breeding colonies were found in 2004 and 2007; Box C indicates the Wuzhishan archipelago and islets B, C and D where Chinese Crested Tern breeding colonies were found in 2008 and 2009. 
islands B and C in 2008, and on islands C and D in 2009. The government of Zhejiang established the Wuzhishan Archipelago Bird Provincial Natural Reserve in 2001, due to the fact that Blacktailed Gulls and Chinese Egrets formed large breeding colonies on these islands (Wang et al. 2008).

A breeding colony of Chinese Crested Terns was first found on the Jiushan archipelago on I August 2004, when the colony was at the incubation stage (Chen et al. 2005). Unfortunately all eggs and chicks were destroyed by two typhoons in succession on 12 August and 18 August 2004. In mid-June 2007, we rediscovered the breeding colony at the incubation stage on the Jiushan archipelago. One week after our discovery, local fishermen collected the Chinese Crested Tern eggs and, once again, reproduction completely failed.

During the 2008 and 2009 breeding seasons, we visited the breeding colonies at the Wuzhishan archipelago every 2-4 days, from mid-May until the end of September, and recorded settlement patterns, timing of nest initiation, dates of egg laying, clutch size and dates of hatching and breeding success. We were able to easily observe the colonies and identify the breeding Chinese Crested Terns from a boat with 8-10x binoculars due to the fact that all three breeding islets in 2008 and 2009 were lower than $30 \mathrm{~m}$ in elevation and all nesting zones of the Chinese Crested Tern were located on the lower sides of the islets. We landed on the islets to obtain data on clutch size, nest site selection and breeding success. Diet was assessed by the collection of regurgitated pellets and fish remains at the breeding grounds and by photographs taken while birds were feeding or transporting prey in their beaks during the chick-rearing period. With continuous observation, we obtained data on length of incubation shifts, chick-rearing, location of feeding grounds and food provisioning of the young during the day (06hoo-19hoo) on 12 and 25 July, 16 and 29 August 2008 and 2, 3 and 20 July 2009. We estimated foraging distances by recording the foraging sites with GPS and measured distances using Google Earth ${ }^{\mathrm{TM}}$. Additionally, we obtained incubation information via an automatic digital video recorder system powered by an $80 \mathrm{~W}$ storage battery, which typically was able to supply the recorder with power for more than 24 hours. We obtained six complete video segments dated 22-23 July and 10-11 August 2008; and 5-6, 7-8, 10-11 and 16-17 July 2009.

\section{Results}

\section{Arrival and courtship}

Chinese Crested Terns arrived at Wuzhishan within small flocks of Greater Crested Terns in late May. In 2009, two Chinese Crested Terns were first documented arriving at Wuzhishan on 31 May. On 5 June 2009, the mixed colony rapidly increased to approximately 800 individuals, and settled at the nesting sites. Two days later the mixed colony began to lay eggs. Courtship behaviour was not observed for earlier laying pairs in both the Chinese Crested Terns and Greater Crested Terns, but was observed in the individuals that laid their eggs at a later time or re-laid after the first clutch failed.

\section{Nuptial plumage recession}

The Chinese Crested Terns arrived in nuptial plumage, which is characterised by a black crest on the forehead. In late June, the nuptial plumage of the Chinese Crested Terns began to recede, specifically black feathers on the forehead were gradually replaced by white feathers, and the remaining crest was black only on the nape. Moulting started at the beginning of the forehead and the area around the eyes. In early August, the moult was almost complete, and the Chinese Crested Terns displayed non-breeding plumage.

\section{Colony size}

The number of Chinese Crested Terns at Jiushan in 2004 was approximately 1o breeding pairs within the Greater Crested Tern colony of about 2,000 pairs. In 2007, four pairs of Chinese 
Crested Terns were breeding within a colony of approximately 1,000 pairs of Greater Crested Terns. In 2008, one pair of Chinese Crested Terns, and 315 pairs of Greater Crested Terns bred on islet B; and one pair of Chinese Crested Terns and 166 pairs of Greater Crested Terns bred on islet C. In 2009, one pair of Chinese Crested Terns bred alone on islet C, one pair of Chinese Crested Terns bred with 460 pairs of Greater Crested Terns on islet D.

\section{Nesting site selection}

During a span of four years, six Chinese Crested Tern nests were confirmed. Among the nests, five were found within a large colony of Greater Crested Terns, while only one nest was found alone at islet $\mathrm{C}$ in 2009. The nesting grounds of the mixed colony included grass, rock and a zone of interlaced rock and grass devoid of tall vegetation. The main types of woody vegetation on these islets are deciduous shrubs of the following species: Mallotus japonica, Pueraria lobata, Albizia kalkora and Rubus parvifolius. Like those of Greater Crested Tern, the nests of Chinese Crested Tern were simply a small scrape, usually unlined or sparsely lined with grass. Both species bred in a single colony with their nests densely intermingled. The Chinese Crested Terns seemed to mix in at random with the large colony of Greater Crested Terns and no two pairs of Chinese Crested Terns nested adjacent to each other (Table 1).

\section{Egg laying and clutch size}

The mixed colonies started laying approximately one week after the initial arrival and two days after peak numbers were recorded at the colonies. In 2008, the first egg of the Chinese Crested Tern was recorded at islet B on 19 June and the second was recorded at islet C on 28 June. In 2009, the first egg of the Chinese Crested Tern was found at islet $C$ on 6 June and the second was found at islet D on 14 June. Egg-laying in the same colony was relatively synchronous and occurred almost within one week.

The clutch size of all Chinese Crested Terns confirmed was always one. Eggs of the Chinese Crested Tern displayed no obvious differences in colour or size when compared with eggs of the Greater Crested Tern. In an attempt to avoid extra disturbance, we did not measure the eggs.

Table 1 . Nest site selection and nearest neighbour distance of the breeding Chinese Crested Terns

\begin{tabular}{ccccccc}
\hline Year Islet Islet Vegetation Latitude & Longitude \\
size coverage \\
(ha)
\end{tabular}

${ }^{\mathrm{I}} \mathrm{Y}$ : with vegetation coverage; $\mathrm{N}$ : without any vegetation coverage. ${ }^{2}$ Inner: Inner nest which was located inside of a colony; Perimeter: perimeter nest which was located around the outer edge of a colony; Alone: nesting alone. 


\section{Incubation}

Early clutches were used to derive an average incubation period of the Chinese Crested Tern, which was estimated to be $25-28$ days in 2008 and $22-25$ days in 2009 .

Both sexes of Chinese Crested Tern incubated the eggs, with 5-10 incubation shifts per day. The shifts occurred frequently at dawn, midday and sunset. Videos from our automatic digital video recorder indicated that changeovers in incubating birds seldom occurred during the night.

\section{Chick rearing}

Chinese Crested Tern chicks were first seen on 16 July in 2008 and on 29 June in 2009. The chicks were precocious and semi-nidifugous. Chinese Crested Tern chicks and Greater Crested Tern chicks were distinct, Chinese Crested Tern being black and white and Greater Crested Tern patterned with grey, brown and white plumage.

Chinese Crested Tern chicks were brooded and fed by both parents in the nest for about two days post-hatching, after which the parents escorted them some distance from the colony. Until about two weeks post-hatching, the chicks were protected by their parents, and subsequently a crèche was formed with other Greater Crested Tern chicks, which was guarded by a few adults of both species. At times, the parents were seen wetting the feathers on their underparts in the ocean in order to cool their chicks. The parents foraged within about $5 \mathrm{~km}$ of the breeding islets by plunging into the ocean from a height of 7-10 $\mathrm{m}$. A description of the foraging grounds is shown in Fig. 2. Chinese Crested Terns fed their chicks bill to bill, mostly with small and/or young shoaling fishes, including Tapertail Anchovy Coilia mystus $(n=7,21.9 \%)$, Bombay Duck Harpodon nehereus ( $n=6,18.7 \%)$, Anchovy Coilia sp. $(n=5,15.6 \%)$, Cresthead Cutlassfish Eupleurogrammus muticus $(n=5,15.6 \%)$, Whitebait Hemisalanx prognathus $(n=3,9.4 \%)$, Scad Decapterus sp. $(n=3,9.4 \%)$, Herring Menhaden Clupea pallasi $(n=2,6.2 \%)$ and Tonguesole Cynoglossus sp. $(n=1,3.1 \%)$, etc. Feeding frequency averaged $1.8 \pm 0.7$ times hour $^{-1}(n=20$ hours) in the daytime, and the mean foraging success (frequency of prey capture/ number of dives) was $68.7 \%(n=43$ dives $)$.

Chinese Crested Tern chicks took $31-35$ days to fledge, and the parents fed the chicks well after they had fledged. After fledging, the young were observed practising flying and fishing at sea while guarded by their parents.

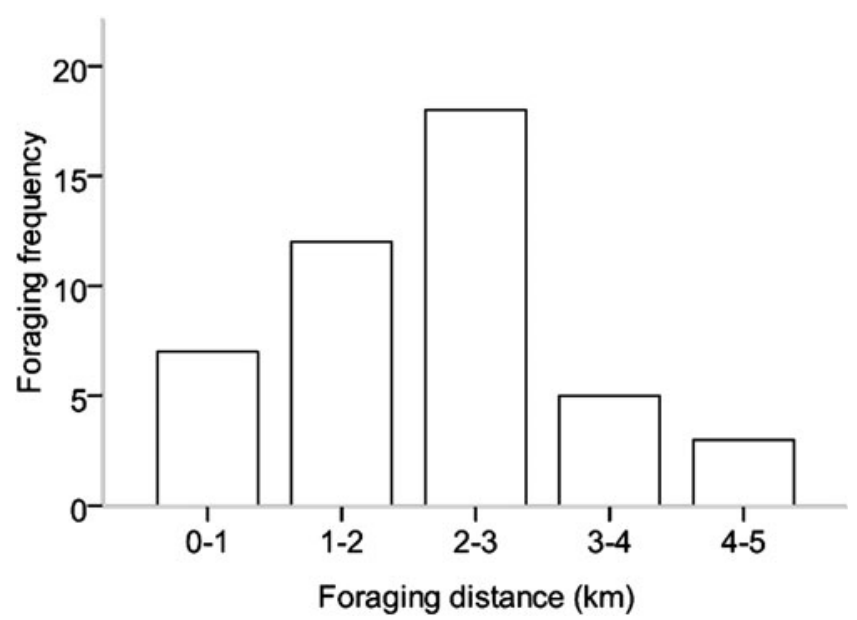

Figure 2. Foraging ground of breeding Chinese Crested Terns in Wuzhishan archipelago. 


\section{Departure}

In mid-August, about one week after chicks were first fledged, the fledglings began to leave the breeding islets with their parents. This gradual departure took about six weeks. The Chinese Crested Terns were last seen on August 29th and the Greater Crested Terns were last seen in late September in 2008. If the breeding colony was completely destroyed, for example by a typhoon in 2004 and by egg collection in 2007, the entire colony would depart the breeding islets within 2-3 days.

\section{Breeding success}

No predation of eggs or chicks was documented, and the Chinese Crested Terns had 100\% breeding success in both 2008 and 2009 .

\section{Discussion}

Currently, most breeding Chinese Crested Terns have been found nesting synchronously within large colonies of Greater Crested Terns. Although there is still no evidence that the two species migrate or winter together, the finding that the two species breed in the same location provides insight into important migration stopover sites and wintering sites along China's southern coast as well as in the costal areas of the South China Sea. More importantly, these findings provide important evidence relevant to search and monitoring, and ultimately the conservation of breeding Chinese Crested Terns in the future.

Individual Chinese Crested Terns were first sighted at the Minjiang Estuary on the northern Fujian coast, China, generally in mid-April, but the start of breeding documented at both breeding sites was late May or early June (Liang et al. 2000). Because most courtship and copulation was not observed when the colony first arrived, we concluded that most birds should have finished mating before arrival and their roost and club sites should have been on nearby beaches or islands. One Chinese Crested Tern was sighted at Chongming Island in Shanghai on 5 September 2004 (Zhang et al. 2004) and it was believed to be from the breeding colony at the Jiushan archipelago in 2004 (Chen et al. 2009). This indicates that some individuals may wander north during the post-breeding period before their southward migration.

On I August 2004, about 10 pairs of Chinese Crested Terns were found during the incubation phase. We were told by the staff of Jiushan Archipelago Natural Reserve that these were the second broods of this colony after their first broods suffering egg collection in June. This renesting trait would enable the prolongation of the breeding period into late September or even into early October.

The mixed breeding population also showed a tendency towards shifting breeding site. In 2004 the mixed breeding population was first found at the Jiushan archipelago (Chen et al. 2005), but then disappeared in 2005 and 2006. In 2007 the birds returned to the Jiushan archipelago, but moved to the Wuzhishan archipelago in 2008 (Chen et al. 2010). In 2009, the colony was still breeding at Wuzhishan, but shifted to another islet. The shifting of breeding sites may partially be caused by human disturbance, especially egg collection, and the underlying causality is worthy of further investigation. Obviously breeding site shifts make it difficult to monitor and safeguard this species but this trait is common in colonially-breeding terns. Accordingly, the conservation strategy should be flexible and monitoring and conservation areas should encompass all potential breeding sites.

Our results showed that the foraging grounds of the Chinese Crested Terns were within about $5 \mathrm{~km}$ range of the breeding islets, and were focused on the area of sea $3 \mathrm{~km}$ around the islets. The major foraging grounds were outside the protected range of the Wuzhishan Archipelago Nature Reserve. The nature reserve was originally established to conserve breeding Black-tailed Gulls 
and Chinese Egrets and expanding the boundary would better protect breeding terns in Wuzhishan.

Although no predation on eggs or chicks was documented during our research, Black-tailed Gulls, raptors, snakes and rats have been regarded as potential predators in mixed breeding colonies (Velarde 1993, Le Corre 2008, Yorio and Quintana 2008, Underhill et al. 2010). In both 2008 and 2009, there were about 1,000 Black-tailed Gulls breeding on three islets of the Wuzhishan archipelago, including islet B and D; Stink Snakes Elaphe carinata were found on islet $\mathrm{D}$ and other islets; rats were found on two other relatively large islets, while the rat situation on the breeding islets of the Crested Terns is unknown; Common Kestrels Falco tinnunculus were recorded $7 \mathrm{~km}$ away at Cen'gan Port on Zhoushan Island during the breeding season. Further monitoring of predation is necessary, and urgent action should be taken to eradicate rats and snakes on seabird breeding islands.

\section{Acknowledgements}

This study was funded by the National Natural Science Foundation of China (No.30570251) and the Zhejiang Provincial Natural Science Foundation (No.Y5090070). We are grateful to the administration of the Zhejiang Jiushan Archipelago Provincial Marine Ecological Nature Reserve and the administration of the Zhejiang Wuzhishan Archipelago Provincial Bird Nature Reserve for their permission to access the breeding islands, and to Xiaodong Li and Sai Wang for their assistance with our field work. Two anonymous referees made useful comments for the revision of the manuscript.

\section{References}

BirdLife International. (2009) Species factsheet: Sterna bernsteini. Downloaded from http://www.birdlife.org on 28/12/2009.

Chen, S. H., Chang, S. H., Liu, Y., Chan, S., Fan, Z. Y., Chen, C. S., Yen, C. W., and Guo, D. S. (2009) Low population and severe threats: status of the Critically Endangered Chinese Crested Tern Sterna bernsteini. Oryx 43: 209-212.

Chen, S. H., Fan, Z. Y., Chen, C. S. and Lu, Y. $W$. (2010) A new breeding site of the Critically Endangered Chinese Crested Tern Sterna bernsteini in the Wuzhishan Archipelago, eastern China. Foktail 26: 132-133.

Chen, S. H., Yan, C. W., Fan, Z. Y., Chen, C. S. and Zhang, F. G. (2005) The breeding colony of Chinese Crested Tern at Jiushan Archipelago in Zhejiang. Chinese J. Zool. 40: 96-97. (In Chinese with English abstract).

Collar, N. J., Andreev, J. V., Chan, S. and Crosby, M. J. (2001) Threatened birds of Asia: The Birdlife International Red Data Book. Cambridge, UK: Birdlife International.

del Hoyo, J., Elliot, A. and Sargatal, J. (1996). Handbook of the birds of the world. Volume 3 Hoatzin to auks. Barcelona, Spain: Lynx Edicions.

Hsu, W. S. and Melville, D. S. (1994) Seabirds of China and adjacent seas status and conservation. Pp. $210-218$ in D. N. Nettleship, J. Burger and M. Gochfeld, eds. Seabirds on islands: threats, case studies and action plans Cambridge, UK: Birdlife International. (Birdlife Conservation Series No.1).

IUCN (2009) IUCN Red List of threatened species. Version 2009.2. <www.iucnredlist. org $>$. Downloaded on 28 December 2009.

Jiang, H. X., Hou, Y. Q., Chu, G. Z., Qian, F. W., Wang, H., Zhang, G. G. and Zheng, G. M. (2010). Breeding population dynamics and habitat transition of Saunders's Gull Larus saundersi in Yancheng National Nature Reserve, China. Bird Conserv. Int. 20: 13-24.

Le Corre, M. (2008) Conservation biology: Cats, rats and seabirds. Nature 451: 134-135.

Liang, C. T., Chang, S. H. and Fang, W. H. (2000) Little known oriental bird: discovery 
of a breeding colony of Chinese Crested Tern. Oriental Bird Club Bull. 32: 18.

Maguire, G. S., Duivenvoorden, A. K., Weston, M. A. and Adams, R. (in press) Provision of artificial shelter on beaches is associated with improved shorebird fledging success. Bird Conserv. Int. doi:10.1017/ So959270910000420

Shaw, T. (1938) The avifauna of Tsingtao and neighbouring districts. Bull. Fan Mem. Inst. Biol. Zool. Ser. 8: 133-222.

Underhill, L. G., Sherley, R. B., Dyer, B. M. and Crawford, R. J. M. (2010) Interactions between snakes and seabirds on Robben, Schaapen and Meeuw Islands, Western Cape province, South Africa. Ostrich 80: 115-118.

Velarde, E. (1993) Predation of nesting larids by Peregrine Falcons at Rasa Island, Gulf of California, Mexico. The Condor 95: 706708.

Wang, Z. D., Lu, Y. W., Chen, S. H., Fan, Z. Y. and Chen, C. S. (2008) Dynamics of breeding waterbird resource and their distributions in Wuzhishan Archipelago, Zhoushan. Sichuan J. Zool. 127: 965-969. (In Chinese).
Yorio, P. and Quintana, F. (2008) Predation by Kelp Gulls Larus dominicanus at a mixedspecies colony of Royal Terns Sterna maxima and Cayenne Terns Sterna eurygnatha in Patagonia. Ibis 139: 536-541.

Yorio, P., Quintana, F., Dell'Arciprete, P. and González-Zevallos, D. (2010) Spatial overlap between foraging seabirds and trawl fisheries: implications for the effectiveness of a marine protected area at Golfo San Jorge, Argentina. Bird Conserv. Int. 20: 320-334.

Zavalaga, C. B., Hardesty, J., Mori, G. P., Chavez-Villavicencio, C. and Tello, A. (2009) Current status of Peruvian Terns Sternula lorata in Perú: threats, conservation and research priorities. Bird Conserv. Int. 19: 175-186.

Zhang, K. J., Yu, X., Gan, X. J. and Melville, D. S. (2004) Chinese Crested Tern at Chongming Dao, Shanghai, China. Birding Asia 2: 66.

Zheng, G. M. and Wang, Q. S. (1998) China Red Data Book of endangered animals: Aves. Beijing, China: Science Press. (In Chinese and English).

\section{S. H. CHEN*, Z. Y. FAN, C. S. CHEN, Y. W. LU}

Zhejiang Museum of Natural History, Hangzhou, Zhejiang, 310o14, China.

*Author for correspondence; e-mail: birdchen@hotmail.com

Received 16 September 2009; revision accepted 14 July 2010; Published online 14 April 2011 